Research

Open Access

\title{
Predicting a low cortisol response to adrenocorticotrophic hormone in the critically ill: a retrospective cohort study
}

\author{
Margriet FC de Jong ${ }^{1}$, Albertus Beishuizen ${ }^{1}$, Jan-Jaap Spijkstra ${ }^{1}$, Armand RJ Girbes ${ }^{1}$, Rob JM \\ Strack van Schijndel ${ }^{1}$, Jos WR Twisk ${ }^{2}$ and AB Johan Groeneveld ${ }^{1}$
}

\begin{abstract}
1Department of Intensive Care, Institute for Cardiovascular Research, Vrije Universiteit Medical Center, De Boelelaan, 1081 HV Amsterdam, The Netherlands

2Department of Epidemiology and Biostatistics, Institute for Cardiovascular Research, Vrije Universiteit Medical Center, De Boelelaan, 1081 HV Amsterdam, The Netherlands
\end{abstract}

Corresponding author: AB Johan Groeneveld, johan.groeneveld@vumc.nl

Received: 3 Apr 2007 Revisions requested: 21 Apr 2007 Revisions received: 30 Apr 2007 Accepted: 24 May 2007 Published: 24 May 2007

Critical Care 2007, 11:R61 (doi:10.1186/cc5928)

This article is online at: http://ccforum.com/content/11/3/R61

(c) 2007 de Jong et al.; licensee BioMed Central Ltd.

This is an open access article distributed under the terms of the Creative Commons Attribution License (http://creativecommons.org/licenses/by/2.0), which permits unrestricted use, distribution, and reproduction in any medium, provided the original work is properly cited.

\begin{abstract}
Introduction Identification of risk factors for diminished cortisol response to adrenocorticotrophic hormone (ACTH) in the critically ill could facilitate recognition of relative adrenal insufficiency in these patients. Therefore, we studied predictors of a low cortisol response to ACTH.

Methods A retrospective cohort study was conducted in a general intensive care unit of a university hospital over a three year period. The study included 405 critically ill patients, who underwent a $250 \mu \mathrm{g} \mathrm{ACTH}$ stimulation test because of prolonged hypotension or need for vasopressor/inotropic therapy. Plasma cortisol was measured before and 30 and 60 min after ACTH injection. A low adrenal response was defined as an increase in cortisol of less than $250 \mathrm{nmol} / \mathrm{l}$ or a peak cortisol level below $500 \mathrm{nmol} / \mathrm{l}$. Various clinical variables were collected at admission and on the test day.
\end{abstract}

Results A low ACTH response occurred in $63 \%$ of patients. Predictors, in multivariate analysis, included sepsis at admission, low platelets, low $\mathrm{pH}$ and bicarbonate, low albumin levels, high Sequential Organ Failure Assessment score and absence of prior cardiac surgery, and these predictors were independent of baseline cortisol and intubation with etomidate. Baseline cortisol/albumin ratios, as an index of free cortisol, were directly related and increases in cortisol/albumin were inversely related to disease severity indicators such as the Simplified Acute Physiology Score II and Sequential Organ Failure Assessment score (Spearman $r=-0.21 ; P<0.0001$ ).

Conclusion In critically ill patients, low $\mathrm{pH} /$ bicarbonate and platelet count, greater severity of disease and organ failure are predictors of a low adrenocortical response to ACTH, independent of baseline cortisol values and cortisol binding capacity in blood. These findings may help to delineate relative adrenal insufficiency and suggest that adrenocortical suppression occurs as a result of metabolic acidosis and coagulation disturbances.

\section{Introduction}

Acute and severe illness is accompanied by increased serum levels of adrenocorticotrophic hormone (ACTH) and cortisol [1-21]. Even elevated levels may be too low for the level of physiological stress and may be associated with diminished adrenal responsiveness to additional stress, so-called relative adrenal insufficiency (RAI). The most commonly used test to assess adrenal function is the short ACTH stimulation test, in which serum cortisol is measured at baseline and up to $60 \mathrm{~min}$ after intravenous administration of $250 \mu \mathrm{g}$ of synthetic ACTH
[2-4,6-12,14,15,17-21]. A wide range exists in the prevalence of RAl among critically ill patients, varying from $0 \%$ to $77 \%$ [1$15,17-20,22,23]$. This is partly due to the heterogeneity of case-mix and of criteria for presumably insufficient cortisol response to $\mathrm{ACTH}$, although a low response is most commonly empirically defined as an increase of less than 250 $\mathrm{nmol} / \mathrm{l}(9 \mu \mathrm{g} / \mathrm{dl})$ [4,8-11,15,17-19,22].

Although there are no specific signs and symptoms of absolute adrenal insufficiency, several factors may be associated

$\overline{\mathrm{ACTH}}=$ adrenocorticotrophic hormone; $\mathrm{CBG}=$ cortisol-binding globulin; GCS = Glasgow Coma Scale score; ICU = intensive care unit; RAI = relative adrenal insufficiency; SAPS $=$ Simplified Acute Physiology Score; SOFA = Sequential Organ Failure Assessment. 
with RAI [5,7-10,12,13,15,22-24]. Remarkably, the literature is scarce and highly controversial on predictors and manifestations of RAl. Factors that are potentially associated with a low adrenal response are the presence of sepsis and shock $[2,4-9,11-13,15,16,19,22,24]$, high lactate [10], hypoalbuminaemia $[14,19]$, use of etomidate for intubation, mechanical ventilation and a low arterial oxygen tension/fractional inspired oxygen ratio $[7,16,20,22,24,25]$, antifungal agents [26], high percentage of eosinophils $[8,12,13,24]$, low sodium and glucose $[12,13]$, and severe underlying disease or organ failure $[7,9,10,16,22,23]$. However, it is unknown whether these factors are interdependent [22]. In addition, low albumin and cortisol-binding globulin (CBG) levels may lower binding capacity in blood, and this may decrease total but maintain free cortisol levels. Hence, total cortisol level may be a poor indicator of whether adrenal cortisol secretion is adequate for the degree of physiologic stress exhibited by critically ill patients [6,14,16,19,27-29]. Indeed, although ACTH has no effect on albumin or CBG levels, the rise in total cortisol may be lower for a given rise in free cortisol when binding capacity is low $[14,19,28]$. Delineation of predictors and characteristics of RAl may help the clinician to select patients for ACTH testing. This may be important, because the results of the ACTH test may help to guide therapy with corticosteroids and thereby improve outcomes, particularly in vasopressor-refractory septic shock, although this is contoversial $[6,8,9,11,13,17]$.

With the aim being to enhance understanding of RAl, the present study was undertaken to evaluate predictors of a low ACTH-induced cortisol response (exhibited by the so-called low responders), taking into account the severity of illness, baseline cortisol levels and hypoalbuminaemia. Therefore, a retrospective cohort study was conducted in 405 critically ill patients in whom an ACTH test was performed during the course of disease in our intensive care unit (ICU). The results of this analysis suggest that low $\mathrm{pH} /$ bicarbonate and low platelets, and greater severity of disease and organ failure are predictors of a subnormal increase in serum cortisol upon ACTH stimulation in a large series of critically ill patients; furthermore, these predictors were independent of sepsis, baseline cortisol and cortisol binding.

\section{Materials and methods Study population and adrenocorticotrophic hormone test}

The present retrospective cohort study was conducted in the ICU of a teaching hospital (VU University Medical Center, Amsterdam, The Netherlands) over a period of three years. The study retrospectively included all patients admitted during this period who underwent a short ACTH (tetracosactidehexa-acetate; Synacthen ${ }^{\circledR}$; Novartis Pharma, Basel, Switzerland) stimulation test and for whom cortisol levels at baseline and 30 and $60 \mathrm{~min}$ after administration of $250 \mu \mathrm{g} \mathrm{ACTH}$ intravenously were available. The need for informed consent was waived because the test was performed on clinical and not investigational grounds. The Dutch legislation does not require informed consent for retrospective studies, provided that the results are anonymous. The test was performed in any patient who was suspected of having some degree of adrenocortical dysfunction on the basis of prolonged hypotension $>6$ hours requiring repeated fluid challenges) or need for vasopressors or inotropic drugs. Blood samples for serum cortisol measurement were taken immediately before $(t=0)$, and $30 \mathrm{~min}(t=$ 30) and $60 \mathrm{~min}(\mathrm{t}=60)$ after intravenous injection of ACTH. Serum cortisol was measured by competitive immunoassay (ASC-180 System; Bayer Diagnostics, Mijdrecht, The Netherlands). The coefficients of variation for this measurement are $3 \%$ for intra-assay variation and $6 \%$ for the interassay variation, and the detection limit is $30 \mathrm{nmol} / \mathrm{l}(500 \mathrm{nmol} / \mathrm{l}=18 \mu \mathrm{g} / \mathrm{dl})$. Whether treatment with corticosteroids was initiated after the test was at the discretion of the intensivists.

\section{Data collection}

On the day of admission, general characteristics including age, sex, type of admission and underlying disease were recorded. International Classification of Disease-10 definitions were used for common clinical conditions at admission. The severity of illness was assessed by calculating the Simplified Acute Physiology Score (SAPS) II (range 0 to 163) and its associated predicted hospital mortality [30] and the Sequential Organ Failure Assessment (SOFA) score (range 0 to 24) [31], both at admission and on the day of the ACTH test, including haemodynamic, pulmonary, renal, neurological, infectious and biochemical parameters. Multiple organ dysfunction was defined as a SOFA score of 7 or greater. The worst values within a 24 hour period were used to calculate the scores. Missing values were regarded as normal. Sepsis at the ACTH test day was defined as the presence of systemic inflammatory response syndrome with a positive microbiological local (trachea, urine, or other) or blood culture, or both. Systemic inflammatory response syndrome was defined was a temperature above $38^{\circ} \mathrm{C}$ or below $35.5^{\circ} \mathrm{C}$, a leucocyte count above $12 \times 10^{9} / \mathrm{l}$ or below $4 \times 10^{9} / \mathrm{l}$, a heart rate above 90 beats/min, and a respiratory rate above 20 breaths/min or need for mechanical ventilation.

Prior use of drugs that may interfere with adrenocortical function, including corticosteroids and antifungal agents [26], from one month before until the test day was reported, as well as the day of intubation. Etomidate is often used to facilitate intubation in our institution. Interventions such as type and dose of inotropics, treatment with corticosteroids, mechanical ventilation and renal replacement therapy were reported, as were positive cultures of trachea, urine, blood and other local sites of infection from seven days before to the day of the ACTH test. The Glasgow Coma Scale (GCS) score recorded was the GCS before sedation in patients on sedatives.

A low response to ACTH in critical illness (RAI) was defined as a cortisol increase of less than $250 \mathrm{nmol} / \mathrm{l}[4,8-11,15,17$ - 
$19,22]$ or a peak level below $500 \mathrm{nmol} / \mathrm{l}[2,4,5,14,21]$. To estimate free cortisol at baseline and its increase following ACTH stimulation, values were normalized for serum albumin (cortisol/albumin ratio) when available $(n=332)$. Mortality was defined as death in the ICU until day 28 after admission, or as hospital mortality.

\section{Statistical analysis}

We conducted a Fisher's exact test for categorical variables and a Mann-Whitney $U$-test for continuous variables (SPSS version 11; SPSS Inc., Chicago, IL, USA). All variables differing among groups at a $P<0.10$ level and available for at least $95 \%$ (model 1 ) or $75 \%$ or more (model 2 ) of the patients were entered into a backward stepwise multiple logistic regression model with low ACTH response (either a low increase [model a] or peak [model b]) as the dependent variable. Hence, models $1 \mathrm{a}$ and $1 \mathrm{~b}$ (for low increase and peak, respectively) did not include albumin levels, whereas models $2 a$ and $2 b$ did. When variables were recorded both on admission and on the test day, such as SAPS II and SOFA scores, variables recorded on the test day were included only, and either the presence of sepsis on admission or on the test day was considered. The Hosmer-Lemeshow test was used to evaluate the goodnessof-fit. Odds ratios ( $95 \%$ confidence intervals) were calculated for categorical data. Final prediction models were validated using a bootstrap method for 1,000 replicates (Stat version 9; StataCorp LP, College Station, TX, USA). We identified the maximum number of replicates (validity) as $100 \%$ minus the minimum percentage (at 5\%, 10\%, 20\%, 50\%, 80\%, 90\% and $95 \%$ ) of replicates to achieve statistical significance for each predictor. The Kruskal-Wallis test was used to compare baseline cortisol levels and increases, normalized for albumin levels, in predefined strata of SAPS II and SOFA scores. Data are expressed as median (range). A two-sided $P<0.05$ was considered to indicate statistical significance, and exact $P$ values are given unless they are less than 0.0001 .

\section{Results \\ Patient characteristics}

In all, 405 patients were included. Age and sex distribution and mortality rate among the study population and all other patients ( $n=3,953$ ) admitted to our ICU during the study period did not differ. However, fewer patients in the study population were admitted after trauma and surgery $(P<0.0001)$ and more were admitted after heart surgery or cardiopulmonary resuscitation, with respiratory failure, shock, renal failure $(P<0.0001)$, or sepsis $(P=0.002)$. Table 1 shows the clinical characteristics of responders and low responders (58\% for an increase in cortisol $<250 \mathrm{nmol} / \mathrm{l}, 32 \%$ for peak cortisol $<500$ $\mathrm{nmol} / \mathrm{l}$, and $63 \%$ for either). Low responders were more often admitted with sepsis, and their admission SAPS II and SOFA scores were higher than in responders. Accordingly, mortality was higher in low responders with an increase below 250 $\mathrm{nmol} / \mathrm{l}$, although they were more likely to have received corticosteroids.

\section{Adrenocorticotrophic hormone test}

For the entire population, median (range) baseline cortisol was $360 \mathrm{nmol} / \mathrm{l}(30-1,870 \mathrm{nmol} / \mathrm{l})$, the median cortisol increase was $210 \mathrm{nmol} / \mathrm{l}(-180$ to $+1,015 \mathrm{nmol} / \mathrm{l})$, and median peak cortisol was $610 \mathrm{nmol} / \mathrm{l}$ (30 to 1,950 nmol/l). Table 2 describes lower cortisol/albumin ratios in low responders, among others.

\section{Predictors}

Table 3 describes statistically significant clinical and biochemical predictors of a diminished ACTH response, as identified in univariate analysis. Availability of data is indicated. Of the 57 patients with sepsis at admission 39 had sepsis on the ACTH test day, whereas 179 additional patients fulfilled sepsis criteria on the ACTH test day $(P=0.021)$. Disease severity was greater in low responders. Heart rate was higher in low responders (cortisol increase $<250 \mathrm{nmol} / \mathrm{l}$ ) and dependency on vasopressor therapy was greater, and they more frequently received ventilatory support at higher fractional inspired oxygen. Of all patients, 96\% were intubated, and intubation was significantly associated with a low response (peak cortisol < $500 \mathrm{nmol} / \mathrm{l}$ ). Low responders (cortisol increase $<250 \mathrm{nmol} / \mathrm{l}$ ) also had a shorter interval between admission/intubation and the ACTH test than did responders. In low responders (cortisol increase $<250 \mathrm{nmol} / \mathrm{l}$ ), lower urinary production was accompanied by higher serum creatinine and urea levels. The $\mathrm{pH}$ and bicarbonate concentrations were lower in low responders. Furthermore, they had lower platelet counts and albumin levels, and those with a cortisol increase below 250 $\mathrm{nmol} / \mathrm{l}$ also had lower glucose and a lower percentage of eosinophils in blood smears.

\section{Correlations and multivariate analyses}

There was little relation between increases in cortisol and baseline values (Spearman $r\left[r_{\mathrm{s}}\right]=-0.17 ; P=0.001$ ). Both baseline cortisol values and increases were somewhat related directly to albumin levels (minimum $r_{\mathrm{s}}=0.17 ; P=0.002$ ). Baseline and increases in cortisol levels were related directly and inversely to SAPS II (minimum $r_{\mathrm{s}}=0.25, P<0.0001$ ), respectively, and SOFA scores (minimum $r_{\mathrm{s}}=0.12 ; P=$ $0.015)$. Figure 1 shows the relation between strata of SAPS II scores and baseline and increases in the cortisol/albumin ratio (as an index of free cortisol), which suggests that a relation exists between severity of illness on the one hand and free cortisol and diminished rises in cortisol upon ACTH stimulation on the other hand (minimum $r_{\mathrm{s}}=-0.22 ; P<0.0001$ ). Similarly, strata of SOFA scores exhibited direct and inverse relations with baseline cortisol/albumin ratios and $\mathrm{ACTH}$-induced increases in cortisol/albumin $(P=0.003$ and $P=0.001)$, respectively. Increases in cortisol and in cortisol/albumin ratio were related to platelet counts, $\mathrm{pH}$ and bicarbonate $(P=$ 0.006 or lower).

Table 4 shows the results of multivariate analyses, using variables available in $95 \%$ or more (models $1 \mathrm{a}$ and $1 \mathrm{~b}$ ) or $75 \%$ or more (models $2 \mathrm{a}$ and $2 \mathrm{~b}$ ) of patients, conducted to identify 
Critical Care Vol 11 No 3 de Jong et al.

Table 1

\begin{tabular}{|c|c|c|c|c|c|c|c|c|}
\hline Characteristic & $\begin{array}{l}\text { Increase } \\
\geq 250 \mathrm{nmol} / \mathrm{l} \\
(n=170)\end{array}$ & $\begin{array}{l}\text { Increase } \\
<250 \mathrm{nmol} / \mathrm{l} \\
(n=235)\end{array}$ & $P$ & $\begin{array}{l}\text { OR } \\
(95 \% \mathrm{Cl})\end{array}$ & $\begin{array}{l}\text { Peak } \geq 500 \mathrm{nmol} / \mathrm{l} \\
(n=276)\end{array}$ & $\begin{array}{l}\text { Peak < }<500 \\
\text { nmol// } \\
(n=129)\end{array}$ & $P$ & $\begin{array}{l}\text { OR } \\
(95 \% \mathrm{Cl})\end{array}$ \\
\hline Age (years) & $63(17-88)$ & $65(15-93)$ & & & $65(17-93)$ & $61(15-89)$ & & \\
\hline Sex (male/female) & $\begin{array}{l}110(65) / 60 \\
(35)\end{array}$ & $\begin{array}{l}151(64) / 84 \\
(36)\end{array}$ & & & 169 (61)/107 (39) & $92(71) / 37(29)$ & 0.058 & $\begin{array}{l}0.64 \\
(0.40-1.00)\end{array}$ \\
\hline \multicolumn{9}{|l|}{ Underlying disease } \\
\hline Cardiovascular & $92(54)$ & $99(42)$ & 0.020 & $\begin{array}{l}0.62 \\
(0.42-0.92)\end{array}$ & $138(50)$ & $53(41)$ & & \\
\hline Renal & $2(1)$ & $6(3)$ & & & $4(1)$ & $4(3)$ & & \\
\hline Pulmonary & $10(6)$ & $20(9)$ & & & $21(8)$ & $9(7)$ & & \\
\hline Hepatic & $1(1)$ & $12(5)$ & 0.010 & $\begin{array}{l}9.09 \\
(1.17-70.63)\end{array}$ & 7 (3) & $6(5)$ & & \\
\hline Gastrointestinal & $11(6)$ & $26(11)$ & & & $19(7)$ & $18(14)$ & 0.026 & $\begin{array}{l}2.19 \\
(1.11-4.33)\end{array}$ \\
\hline Neurological & $13(8)$ & $15(6)$ & & & $20(7)$ & $8(6)$ & & \\
\hline Endocrinological & $18(11)$ & $27(11)$ & & & $35(13)$ & $10(8)$ & & \\
\hline Cancer & $19(11)$ & $32(14)$ & & & $35(13)$ & $16(12)$ & & \\
\hline \multicolumn{9}{|l|}{ Admission syndromes ${ }^{a}$} \\
\hline $\begin{array}{l}\text { Trauma and post- } \\
\text { operative }\end{array}$ & $79(46)$ & $92(39)$ & & & $114(43)$ & $57(44)$ & & \\
\hline Cardiac surgery & 39 (23) & $26(11)$ & 0.002 & $\begin{array}{l}0.42 \\
(0.24-0.72)\end{array}$ & $47(17)$ & $18(14)$ & & \\
\hline Vascular surgery & $8(5)$ & $17(7)$ & & & $17(6)$ & $8(6)$ & & \\
\hline Respiratory failure & $47(28)$ & $72(31)$ & & & $85(31)$ & $34(26)$ & & \\
\hline Post-CPR & $14(8)$ & $10(4)$ & & & $20(7)$ & 4 (3) & & \\
\hline Sepsis & $12(7)$ & $45(19)$ & $\begin{array}{l}<0.0 \\
001\end{array}$ & $\begin{array}{l}3.12 \\
(1.59-6.10)\end{array}$ & $31(11)$ & $26(20)$ & 0.021 & $\begin{array}{l}2.00 \\
(1.13-3.52)\end{array}$ \\
\hline Shock & $5(3)$ & $16(7)$ & & & $16(6)$ & $5(4)$ & & \\
\hline Renal insufficiency & $6(4)$ & $11(5)$ & & & 9 (3) & $8(6)$ & & \\
\hline Coma & $3(2)$ & $8(3)$ & & & $8(3)$ & $3(2)$ & & \\
\hline Other & $35(21)$ & $58(25)$ & & & $49(18)$ & $26(20)$ & & \\
\hline Admission SAPS II & $36(0-95)$ & $44(9-94)$ & $\begin{array}{l}<0.0 \\
001\end{array}$ & & 39 (7-95) & $42(0-94)$ & & \\
\hline Admission SOFA & $8(0-17)$ & $9(0-22)$ & 0.001 & & $8(0-18)$ & $9(0-22)$ & 0.018 & \\
\hline CS after test & $102(60)$ & $185(79)$ & $\begin{array}{l}<0.0 \\
001\end{array}$ & $\begin{array}{l}2.47 \\
(1.59-3.82)\end{array}$ & $181(66)$ & $106(82)$ & 0.001 & $\begin{array}{l}2.42 \\
(1.45-4.05)\end{array}$ \\
\hline ICU mortality & $24(14)$ & $63(27)$ & 0.002 & $\begin{array}{l}0.45 \\
(0.27-0.75)\end{array}$ & $54(20)$ & $33(26)$ & & \\
\hline $\begin{array}{l}\text { In CS-treated } \\
\text { patients }\end{array}$ & $16(16)$ & $48(26)$ & 0.054 & $\begin{array}{l}0.53 \\
(0.28-0.99)\end{array}$ & $37(13)$ & $27(21)$ & & \\
\hline $\begin{array}{l}\text { In non-CS-treated } \\
\text { patients }\end{array}$ & $8(12)$ & $15(30)$ & 0.018 & $\begin{array}{l}0.31 \\
(0.12-0.81)\end{array}$ & $17(6)$ & $6(5)$ & & \\
\hline Hospital mortality & $48(28)$ & $109(46)$ & $\begin{array}{l}<0.0 \\
001\end{array}$ & $\begin{array}{l}0.45 \\
(0.30-0.69)\end{array}$ & $103(37)$ & $54(42)$ & & \\
\hline
\end{tabular}

Values are expressed as median (range) or number (\%), where appropriate. Exact $P$ values are given where $P<0.10$. aPatients may have more than one condition. All variables were scored for $100 \%$ of the patients. $500 \mathrm{nmol} / \mathrm{l}=18 \mu \mathrm{g} / \mathrm{dl}$ cortisol. $\mathrm{Cl}$, confidence interval; CPR,

cardiopulmonary resuscitation; CS, corticosteroids; ICU, intensive care unit; SAPS, Simplified Acute Physiology Score; SOFA, Sequential Organ Failure Assessment. 
Table 2

\begin{tabular}{|c|c|c|c|c|c|c|}
\hline Parameter & $\begin{array}{l}\text { Increase } \geq 250 \\
\text { nmol/I } \\
(n=170)\end{array}$ & $\begin{array}{l}\text { Increase }<250 \\
\text { nmol/l } \\
(n=235)\end{array}$ & $P$ & $\begin{array}{l}\text { Peak } \geq 500 \mathrm{nmol} / \mathrm{l} \\
(n=276)\end{array}$ & $\begin{array}{l}\text { Peak }<500 \mathrm{nmol} / \mathrm{l} \\
(n=129)\end{array}$ & $P$ \\
\hline Baseline cortisol $(\mathrm{nmol} / \mathrm{l})$ & $323(40-1160)$ & $375(30-1870)$ & 0.014 & $435(49-1870)$ & $220(30-475)$ & $<0.0001$ \\
\hline Baseline cortisol/albumin (nmol/g) & $21.6(2-66)$ & $29.0(1-198)$ & $<0.0001$ & $28.6(2-198)$ & $16.5(1-62)$ & $<0.0001$ \\
\hline $\mathrm{t}=30$ cortisol $(\mathrm{nmol} / \mathrm{l})$ & $635(255-1740)$ & $475(30-1910)$ & $<0.0001$ & $640(290-1910)$ & $350(30-485)$ & $<0.0001$ \\
\hline $\mathrm{t}=60$ cortisol $(\mathrm{nmol} / \mathrm{l})$ & $710(335-1720)$ & $510(30-1950)$ & $<0.0001$ & $690(350-1950)$ & $375(30-495)$ & $<0.0001$ \\
\hline Peak cortisol $(\mathrm{nmol} / \mathrm{l})$ & $710(335-1740)$ & $520(30-1950)$ & $<0.0001$ & $695(500-1950)$ & $385(30-495)$ & $<0.0001$ \\
\hline Peak $<500 \mathrm{nmol} / \mathrm{l}$ & $20(12)$ & $109(46)$ & $<0.0001$ & na & na & \\
\hline Cortisol increase $(\mathrm{nmol} / \mathrm{l})$ & $358(250-1015)$ & $130(-180-245)$ & $<0.0001$ & $268(-180-1015)$ & $135(-100-373)$ & $<0.0001$ \\
\hline Cortisol increase/albumin (nmol/g) & $21.7(8-54)$ & $8.0(-8-43)$ & $<0.0001$ & $17.1(-8-54)$ & $9.7(-8-43)$ & $<0.0001$ \\
\hline Cortisol increase $<250 \mathrm{nmol} / \mathrm{l}$ & na & na & $126(46)$ & $109(84)$ & $<0.0001$ & \\
\hline
\end{tabular}

Values are expressed as median (range) or number (\%), where appropriate. Exact $P$ values are given where $P<0.10500 \mathrm{nmol} / \mathrm{l}=18 \mu \mathrm{g} / \mathrm{dl}$ cortisol. na, not applicable.

factors that predict low increases or peaks. The results show that high SOFA score, low platelet count, low $\mathrm{pH}$, and low bicarbonate and low albumin levels were, in descending order, the most frequent predictors of low response, and these predictors were independent of each other and baseline cortisol. In contrast, prior cardiac surgery protected. Modeling the data with inclusion of sepsis on the test day rather than at admission to predict a cortisol increase below $250 \mathrm{nmol} / \mathrm{l}$ yielded similar results for platelet count, $\mathrm{pH}$, albumin and cardiac surgery, independently of SOFA, baseline cortisol, time from admission/intubation until test and use of etomidate.

\section{Discussion}

The main finding of the present study, comprising the largest series of ACTH tests in general ICU patients thus far reported, is the value of a set of clinical parameters for predicting RAI during critical illness. The set consisted of low arterial $\mathrm{pH}$, low bicarbonate, low platelet count and high SOFA score, particularly in noncardiac (surgical) patients, and these predictors were independent of sepsis, interval until testing, intubation with etomidate, baseline cortisol and albumin levels. The results not only help in predicting a diminished response to ACTH stimulation but also provide insight into the pathophysiological mechanisms of a low response and significance of RAl. That low $\mathrm{pH} /$ bicarbonate is predictive of RAl can be explained by underlying circulatory insufficiency and perhaps adrenal hypoperfusion, or by metabolic acidosis directly suppressing adrenal cortisol synthesis [32]. However, lactate levels did not differ among responders and low responders, thereby arguing against the former. The contribution of low platelets to a low response, independent of sepsis or infection, may be caused by circulating factors promoting platelet aggregation and impairing adrenal function; alternatively, it may be associated with adrenal microcirculatory thrombosis or bleeding, which are known to impair cortisol synthesis [33].
We used a cortisol increase of $250 \mathrm{nmol} / \mathrm{l}$ and a peak level of $500 \mathrm{nmol} / \mathrm{l}$ as the cutoff values to define RAI [2,4,5,8$11,14,15,17-19,21,22]$, even though our data indicate a continuum of baseline cortisol and increases in cortisol values rather than a bimodal distribution. We did not exclude patients with very low baseline cortisol values or increases, which are partly attributable to low protein binding during critical illness $[14,19]$; this contributes to poor differentiation between absolute adrenocortical dysfunction and RAI in these patients. Although widely varying definitions and cutoff values have been used, and corresponding prevalences of RAI greatly differ between studies, an increase of less than $250 \mathrm{nmol} / \mathrm{l}$ appears to be associated with the greatest predictive value for steroid responsiveness in septic shock and mortality, although this is controversial $[6,8,9,11,13,17]$. In any case, low increases can only partly be attributed to high baseline cortisol values, and the prevalence of RAI in the present study is in accordance with findings reported in the literature $[6,7,9,10,13,15,22,23]$.

None of the classic signs and symptoms associated with adrenal insufficiency (for instance, fever, hyponatraemia and hyperkalaemia) was predictive of RAI in our patients, even though the blood glucose level was somewhat lower in low responders. Other investigators demonstrated an association of relative eosinophilia with low response to $\mathrm{ACTH}[8,12,13,24]$. A lower percentage of eosinophils among low responders in our study could be attributed to somewhat higher baseline cortisol levels. In any case, advanced age was not a predictor, which is in accordance with many other reports $[8,13,15,22]$. Although prior cardiovascular disease or cardiac surgery was not associated with RAl, sepsis at admission, which was already present at admission in about $20 \%$ of low responders, was an independent predictor for a low response. This is in accordance with the literature, which indicates that there is a 
Critical Care Vol 11 No 3 de Jong et al.

Table 3

\begin{tabular}{|c|c|c|c|c|c|c|c|c|}
\hline Factor & $\begin{array}{l}\text { Increase } \\
\geq 250 \mathrm{nmol} / \mathrm{l} \\
(n=170)\end{array}$ & $\begin{array}{l}\text { Increase } \\
<250 \mathrm{nmol} / \\
\text { I } \\
(n=235)\end{array}$ & $P$ & $\begin{array}{l}\text { OR } \\
(95 \% \mathrm{Cl})\end{array}$ & $\begin{array}{l}\text { Peak } \geq 500 \\
\mathrm{nmol} / / \\
(n=276)\end{array}$ & $\begin{array}{l}\text { Peak }<500 \\
\text { nmol//I } \\
(n=129)\end{array}$ & $P$ & $\begin{array}{l}\text { OR } \\
(95 \% \mathrm{Cl})\end{array}$ \\
\hline $\begin{array}{l}\text { Time from admission } \\
\text { (days)a }\end{array}$ & $5(1-77)$ & $3(1-92)$ & $<0.0001$ & & $4(1-77)$ & $4(1-92)$ & & \\
\hline Intubationa & $161(95)$ & $229(97)$ & & & $261(95)$ & $129(100)$ & 0.004 & na \\
\hline Time until test (days) ${ }^{a}$ & $4(0-76)$ & $2(0-70)$ & 0.001 & & $3(0-76)$ & $3(0-70)$ & & \\
\hline Fluconazole ${ }^{a}$ & $12(7)$ & $29(12)$ & 0.077 & $\begin{array}{l}1.85 \\
(0.92-3.75)\end{array}$ & $22(8)$ & $19(15)$ & 0.050 & $\begin{array}{l}2.00 \\
(1.04-3.83)\end{array}$ \\
\hline Time until test (days) & $4(0-15)$ & $7(0-63)$ & 0.038 & & $6(0-63)$ & $5(0-53)$ & & \\
\hline SAPS $\|^{*}$ & $35(7-97)$ & $44(7-100)$ & $<0.0001$ & & $39(9-97)$ & $40(7-100)$ & & \\
\hline SOFA* & $8(0-21)$ & $10(0-21)$ & $<0.0001$ & & $8(0-21)$ & $10(0-21)$ & 0.014 & \\
\hline Multiple organ dysfunction ${ }^{a}$ & $103(61)$ & $194(83)$ & $<0.0001$ & $\begin{array}{l}3.08 \\
(1.95-4.86)\end{array}$ & $192(70)$ & $105(81)$ & 0.016 & $\begin{array}{l}1.92 \\
(1.15-3.19)\end{array}$ \\
\hline Heart rate (beats/min) & $\begin{array}{l}90 \\
(48-146)\end{array}$ & $\begin{array}{l}96 \\
(59-171)\end{array}$ & 0.001 & & $94(48-171)$ & $94(52-146)$ & & \\
\hline Vasopressors/inotropes ${ }^{a}$ & $134(79)$ & $206(88)$ & 0.020 & $\begin{array}{l}1.91 \\
(1.12-3.26)\end{array}$ & $226(82)$ & $114(88)$ & & \\
\hline Mechanical ventilation ${ }^{\mathrm{a}}$ & $152(89)$ & $224(95)$ & 0.031 & $\begin{array}{l}2.41 \\
(1.11-5.25)\end{array}$ & $250(91)$ & $126(98)$ & 0.012 & $\begin{array}{l}4.37 \\
(1.30-14.71)\end{array}$ \\
\hline $\mathrm{FiO}_{2} \mathrm{~b}$ & $\begin{array}{l}0.41 \\
(0.29-1.0)\end{array}$ & $\begin{array}{l}0.50 \\
(0.34-1.0)\end{array}$ & $<0.0001$ & & $\begin{array}{l}0.45 \\
(0.29-1.0)\end{array}$ & $\begin{array}{l}0.49 \\
(0.30-1.0)\end{array}$ & & \\
\hline $\mathrm{PaO}_{2} / \mathrm{FiO}_{2}{ }^{\mathrm{b}}$ & $\begin{array}{l}240 \\
(59-681)\end{array}$ & $\begin{array}{l}203 \\
(44-641)\end{array}$ & 0.005 & & $\begin{array}{l}220 \\
(44-681)\end{array}$ & $\begin{array}{l}225 \\
(77-641)\end{array}$ & & \\
\hline Renal replacement ${ }^{\mathrm{a}}$ & $23(14)$ & $47(20)$ & & & $35(13)$ & $35(27)$ & 0.001 & $\begin{array}{l}2.56 \\
(1.52-4.33)\end{array}$ \\
\hline Urine production $(\mathrm{ml})^{\mathrm{a}}$ & $\begin{array}{l}255 \\
(0-8845)\end{array}$ & $\begin{array}{l}1667 \\
(0-6970)\end{array}$ & $<0.0001$ & & $\begin{array}{l}1989 \\
(0-10140)\end{array}$ & $\begin{array}{l}1697 \\
(0-6970)\end{array}$ & & \\
\hline Creatinine $(\mu \mathrm{mol} / \mathrm{l})^{\mathrm{a}}$ & $\begin{array}{l}92 \\
(23-695)\end{array}$ & $\begin{array}{l}122 \\
(20-1934)\end{array}$ & $<0.0001$ & & $\begin{array}{l}112 \\
(20-1934)\end{array}$ & $\begin{array}{l}116 \\
(36-675)\end{array}$ & & \\
\hline Urea $(\mathrm{mmol} / \mathrm{l})^{\mathrm{b}}$ & $\begin{array}{l}10.2 \\
(0.7-46.3)\end{array}$ & $\begin{array}{l}13.3 \\
(1.5-149)\end{array}$ & 0.018 & & $\begin{array}{l}12.1 \\
(1.0-149)\end{array}$ & $\begin{array}{l}12.4 \\
(0.7-89.8)\end{array}$ & & \\
\hline $\begin{array}{l}\text { Glasgow Coma Scale } \\
\text { score }^{\mathrm{a}}\end{array}$ & $15(3-15)$ & $11(3-15)$ & 0.070 & & $11(3-15)$ & $15(3-15)$ & & \\
\hline Positive other local culture ${ }^{a}$ & $50(29)$ & $88(37)$ & & & $76(28)$ & $62(48)$ & $<0.0001$ & $\begin{array}{l}2.43 \\
(1.58-3.76)\end{array}$ \\
\hline SIRSa & $116(68)$ & $194(83)$ & 0.001 & $\begin{array}{l}2.20 \\
(1.38-3.51)\end{array}$ & $213(77)$ & $97(75)$ & & \\
\hline Sepsis ${ }^{a}$ & $80(47)$ & $138(59)$ & 0.021 & $\begin{array}{l}1.60 \\
(1.08-2.38)\end{array}$ & $147(53)$ & $71(55)$ & & \\
\hline Haemoglobin $(\mathrm{mmol} / \mathrm{l})^{\mathrm{a}}$ & $\begin{array}{l}5.8 \\
(4.0-7.9)\end{array}$ & $\begin{array}{l}5.7 \\
(3.6-9.7)\end{array}$ & & & $5.8(4.0-8.8)$ & $5.6(3.6-9.7)$ & 0.011 & \\
\hline Haematocrita & $\begin{array}{l}0.28 \\
(0.20-0.38)\end{array}$ & $\begin{array}{l}0.27 \\
(0.17-0.44)\end{array}$ & & & $\begin{array}{l}0.28 \\
(0.20-0.43)\end{array}$ & $\begin{array}{l}0.26 \\
(0.17-0.44)\end{array}$ & 0.004 & \\
\hline Platelets $\left(\times 10^{9} /\right)^{a}$ & $\begin{array}{l}192 \\
(20-818)\end{array}$ & $\begin{array}{l}130 \\
(3-756)\end{array}$ & $<0.0001$ & & $173(4-818)$ & $123(3-468)$ & 0.001 & \\
\hline Eosinophils (\%) & $1(0-5)$ & $0(0-4)$ & 0.014 & & $0(0-5)$ & $0(0-1)$ & & \\
\hline Albumin $\left(\mathrm{g} / \mathrm{l}^{\mathrm{b}}\right.$ & $17(6-32)$ & $13(3-34)$ & $<0.0001$ & & $17(3-34)$ & $12(3-32)$ & $<0.0001$ & \\
\hline Bilirubin $(\mu \mathrm{mol} / \mathrm{l}) \mathrm{c}$ & $10(3-176)$ & $14(2-441)$ & 0.001 & & $12(2-280)$ & $12(2-441)$ & & \\
\hline
\end{tabular}


Table 3 (Continued)

Predictors of a low response to adrenocorticotrophic hormone

\begin{tabular}{lllllll}
\hline Arterial $\mathrm{pH}$ & \\
& 7.43 & 7.38 & $<0.0001$ & 7.41 & 7.39 & 0.039 \\
Bicarbonate $(\mathrm{mmol} / \mathrm{l})^{\mathrm{a}}$ & $(7.07-7.56)$ & $(6.89-7.64)$ & & $(6.89-7.64)$ & $(7.02-7.54)$ & \\
& 25.0 & 21.7 & $<0.0001$ & 23.8 & 21.9 & 0.005 \\
Glucose $(\mathrm{mmol} /)^{\mathrm{a}}$ & $(6.6-37.8)$ & $(6.8-37.0)$ & & $(6.6-37.8)$ & $(12.1-33.4)$ & \\
& 7.6 & 7.1 & 0.036 & 7.3 & 7.1 & \\
& $(1.9-35.0)$ & $(2.3-25.8)$ & & $(2.6-35.0)$ & $(1.9-25.8)$ & \\
\hline
\end{tabular}

Values are expressed as median (range) or number (\%), where appropriate. Exact $P$ values are given where $P<0.10$. aData available in $>95 \%$. bData available in $\geq 75 \%$. cData available in $64 \% .500 \mathrm{nmol} / \mathrm{l}=18 \mu \mathrm{g} / \mathrm{dl}$ cortisol. Cl, confidence interval; FiO ${ }_{2}$, inspired fractional oxygen; HR, heart rate; na, not applicable; $\mathrm{PaO}_{2}$, partial arterial oxygen tension; SAPS, Simplified Acute Physiology Score; SIRS, systemic inflammatory response syndrome; SOFA, Sequential Organ Failure Assessment.

high incidence of $\mathrm{RAl}$ in patients with sepsis and shock $[4,5,7$ $9,11-13,16,19,22,24]$. Plasma from patients with septic shock impairs synthesis of corticosteroids by adrenocortical cells [34]. We evaluated predictors of low response in patients who had sepsis at admission and who met criteria for sepsis at the time of the ACTH test separately; these predictors appeared to be similar, in multivariate analyses. Because sepsis on the test day occurred in about $57 \%$ of low responders and was not an independent predictor, we cannot exclude the possibility that RAl also occurred in nonseptic hypotensive patients.

Low responders (cortisol increase $<250 \mathrm{nmol} / \mathrm{l}$ ) were more often treated by vasopressors, which is in agreement with findings reported in the literature $[5,7,8,10,15,22,24]$. Etomidate is commonly used to facilitate endotracheal intubation; it is an inhibitor of $11 \beta$-hydroxylase, which is involved in cortisol synthesis. A single bolus of etomidate has been shown to diminish transiently the response to $\mathrm{ACTH}$ in critically ill patients $[16,20,22,25]$. Indeed, depression of adrenal function by etomidate may be transient, but lasts for at least 24 hours $[20,22,25]$. However, in our study, intubation with the help of etomidate and the interval between intubation and the test were associated with low response in univariate analysis but not in multivariate analysis. Mechanical ventilation did not predict a low ACTH response either, which is in contrast to the literature $[17,24]$. Similarly, prior treatment of fungal infection with fluconazole, which utilizes the cytochrome P450 system for metabolism and which inhibits $11 \beta$-hydroxylase, did not predict RAI in our study; this is in accordance with the literature [26].

\section{Figure 1}
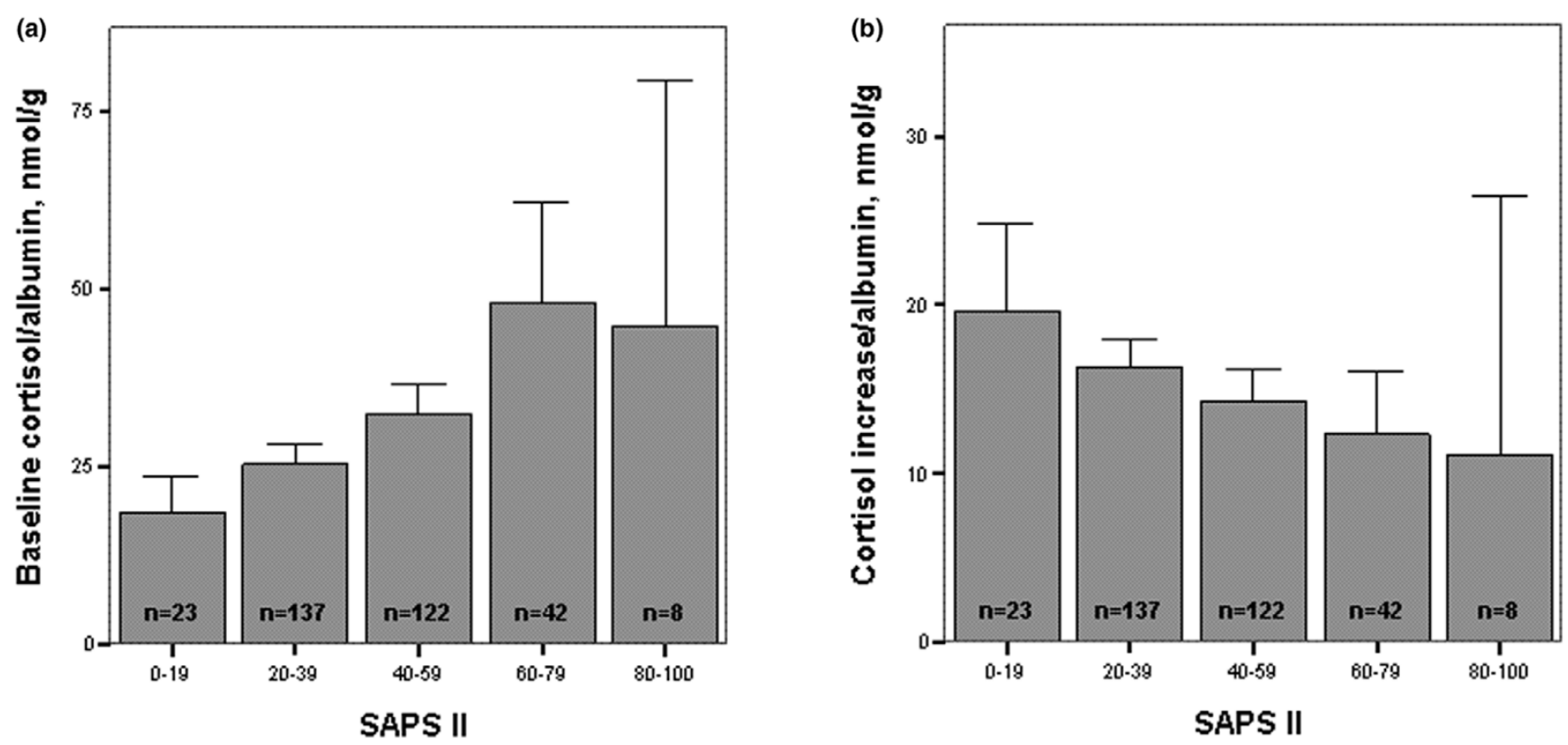

Relation between baseline and ACTH-induced increases in cortisol/albumin and SAPS II score. (a) Association between baseline cortisol/albumin and Simplified Acute Physiology Score (SAPS) II score (five strata; $P<0.0001$, Kruskal-Wallis test). (b) Association between adrenocorticotrophic hormone (ACTH)-induced increases in cortisol/albumin and SAPS II strata $(P=0.002$, Kruskal-Wallis test). 
Table 4

Predictors of a low adrenocortictrophic hormone response in multivariate analysis

\begin{tabular}{|c|c|c|c|c|c|c|}
\hline \multirow[t]{2}{*}{ Factor } & \multicolumn{3}{|c|}{ Increase $<250 \mathrm{nmol} / \mathrm{l}$} & \multicolumn{3}{|c|}{ Peak $<500 \mathrm{nmol} / \mathrm{l}$} \\
\hline & OR (95\% Cl) & $P$ & Validity & & OR $(95 \% \mathrm{Cl})$ & $P$ \\
\hline & \multicolumn{3}{|c|}{ Model 1a $(n=404)$} & \multicolumn{3}{|c|}{ Model 1b $(n=403)$} \\
\hline Positive other local culture & na & & & $2.40(1.32-4.37)$ & 0.004 & $<5 \%$ \\
\hline Sepsis at admission & $2.34(1.13-4.84)$ & 0.022 & $<5 \%$ & na & & \\
\hline SOFA test day & $1.11(1.03-1.18)$ & 0.003 & $50-80 \%$ & $1.11(1.01-1.21)$ & 0.024 & $50-80 \%$ \\
\hline Baseline cortisol (nmol/l) & $1.001(1.000-1.002)$ & 0.045 & $50-80 \%$ & $0.987(0.985-0.990)$ & $<0.0001$ & $>95 \%$ \\
\hline Platelets $\left(\times 10^{9} / \mathrm{l}\right)$ & $0.998(0.996-1.000)$ & 0.031 & $50-80 \%$ & $0.997(0.994-1.000)$ & 0.044 & $50-80 \%$ \\
\hline Bicarbonate (mmol/l) & na & & & $0.91(0.86-0.97)$ & 0.003 & $80-90 \%$ \\
\hline Cardiac surgery & $0.48(0.26-0.86)$ & 0.013 & $90-95 \%$ & na & & \\
\hline \multirow[t]{2}{*}{ Arterial pH } & $0.011(0.001-0.185)$ & 0.002 & $>95 \%$ & na & & \\
\hline & \multicolumn{3}{|c|}{ Model 2a $(n=330)$} & \multicolumn{3}{|c|}{ Model 2b $(n=332)$} \\
\hline SOFA test day & na & & & $1.19(1.09-1.30)$ & $<0.0001$ & $90-95 \%$ \\
\hline Heart rate (beats/min) & $1.015(1.003-1.028)$ & 0.015 & $50-80 \%$ & na & & \\
\hline Platelets (× 109/I) & $0.997(0.995-0.999)$ & 0.009 & $50-80 \%$ & na & & \\
\hline Baseline cortisol (nmol/l) & na & & & $0.986(0.983-0.990)$ & $<0.0001$ & $>95 \%$ \\
\hline Albumin $(\mathrm{g} / \mathrm{l})$ & $0.93(0.90-0.97)$ & 0.001 & $90-95 \%$ & $0.92(0.87-0.97)$ & 0.003 & $80-90 \%$ \\
\hline Cardiac surgery & $0.40(0.20-0.79)$ & 0.008 & $>95 \%$ & na & & \\
\hline Arterial pH & $0.002(0.0001-0.048)$ & $<0.0001$ & $>95 \%$ & na & & \\
\hline
\end{tabular}

Models 1 and 2 included all univariate significant variables that were available in at least $95 \%$ and $75 \%$ of patients, respectively (see text). Validity was assessed by bootstrap analysis (see Materials and methods). Hosmer-Lemeshow tests: model $1 \mathrm{a}: \chi^{2}=9.2$, degrees of freedom (df) $=8, P=$ 0.32 ; model $1 \mathrm{~b}: \chi^{2}=4.4, \mathrm{df}=8, P=0.82$; model $2 \mathrm{a}: \chi^{2}=13.2, \mathrm{df}=8, P=0.11$; and model $2 \mathrm{~b}: \chi^{2}=10.0, \mathrm{df}=8, P=0.26$. Cl, confidence interval; na, not applicable; OR, odds ratio; SOFA, Sequential Organ Failure Assessment.

This study has some limitations. By virtue of the study design and rationale, the patients studied represent a selected group. We did not separately score for head trauma in our patients, which may carry risk for endocrine dysfunction. Nevertheless, a GCS score below 8 in the presence of trauma did not contribute to prediction of a low cortisol response (peak or increase). The CBG and free cortisol levels were not directly measured, and we might have underestimated baseline free cortisol levels and rises upon ACTH stimulation, as pointed out previously $[6,14,16,19,27-29]$. However, we used albumin levels to estimate free cortisol, because albumin may also bind cortisol, albeit to a lesser extent than CBG, and both albumin and CBG levels may decrease to the same extent in critical illness [16,19,27-29]. Hamrahian and coworkers [14] also used blood albumin level as a surrogate marker of plasma cortisol binding capacity. Low albumin levels were associated with low baseline cortisol values and increases. However, hypoalbuminaemia independently increased the risk for a low response, suggesting that the latter was only partly caused by diminished cortisol-binding proteins; Ho and colleagues [19] concurred with this view, but Hamrahian and coworkers [14] attributed a low total cortisol response mainly to low serum cortisol-binding capacity. In groups divided on the basis of the Hamrahian criterion of an albumin level of less than $(n=309)$ or greater than $25 \mathrm{~g} / \mathrm{l}(n=23)$, there were no differences in baseline cortisol values and increases. Moreover, our findings with high baseline levels and low increases in cortisol associated with increasing severity of disease (Figure 1) and organ failure were not affected by cortisol binding, and the multivariate predictors of low responses were independent of baseline cortisol and albumin levels. Some studies [1-3], but not all, indeed suggest that (total) cortisol values increase and ACTH-induced increases diminish with increasing Acute Physiology and Chronic Health Evaluation II score or other disease severity and organ failure scores, unless limited by progressive and severe hypoalbuminaemia and decreased cortisol binding [1$3,7,10,19,21-23]$. Hence, the diminished (total and free) cortisol response to ACTH was a marker of severity of disease in our critically ill patients. Nevertheless, we cannot determine whether the free cortisol response to ACTH was sufficient in 
terms of ability to cope with additional stress. Conversely, the existence of RAl is doubtful when baseline (free) cortisol levels are high or when $250 \mu \mathrm{g} \mathrm{ACTH}$ is regarded as a supraphysiologic stimulus $[5,18,24]$.

\section{Conclusion}

We conclude that low $\mathrm{pH} /$ bicarbonate and low platelets, and increased severity of disease and organ failure were predictors of a subnormal increase in serum cortisol upon ACTH stimulation in a large series of critically ill patients, and these predictors were independent of sepsis, baseline cortisol and cortisol binding. This suggests that adrenocortical suppression occurs as a result of metabolic acidosis and coagulation disturbances. Even though increases in cortisol form a continuum and the cutoff values chosen are relatively arbitrary, our findings may help to better define RAI, which may be associated with increased mortality.

\section{Key messages}

- In a large series of critically ill patients, low $\mathrm{pH} / \mathrm{bicarbo-}$ nate and low platelets, and increased severity of disease and organ failure were predictors of a subnormal increase in serum cortisol upon ACTH stimulation.

- These predictors are independent of sepsis, baseline cortisol and cortisol binding.

- Adrenocortical suppression may be caused, in part, by metabolic acidosis and coagulation disturbances.

\section{Competing interests}

The authors declare that they have no competing interests.

\section{Authors' contributions}

$A B$ participated in the design of the study and helped to draft the manuscript. AG helped to draft the manuscript. JG participated in the design and coordination of the study, and helped to draft the manuscript. JS helped to draft the manuscript. JT participated in the statistical analysis. MJ participated in the design of the study, carried out the data collection, performed the statistical analysis, and drafted the manuscript. RS helped to draft the manuscript.

All authors read and approved the final manuscript.

\section{References}

1. Parker LN, Levin ER, Lifrak ET: Evidence for adrenocortical adaptation to severe illness. J Clin Endocrinol Metab 1985, 60:947-962.

2. Jurney TH, Cockrell JL, Lindberg JS, Lamiell JM, Wade CE: Spectrum of serum cortisol response to ACTH in ICU patients. Chest 1987, 92:292-295.

3. Wade CE, Lindberg JS, Cockrell JL, Lamiell JM, Hunt MM, Ducey $\mathrm{J}$, Jurney $\mathrm{TH}$ : Upon-admission adrenal steroidogenesis is adapted to the degree of illness in intensive care unit patients. $J$ Clin Endocrinol Metab 1988, 67:223-227.

4. Moran JL, Chapman MJ, O'Fatharthaigh MS, Peisach AF, Pannall PR, Leppard P: Hypocortisolaemia and adrenocortical respon- siveness at onset of septic shock. Intensive Care Med 1994, 20:489-495.

5. Soni A, Pepper GM, Wyrwinski PM, Ramirez NE, Simon R, Pina T, Gruenspan H, Vaca CE: Adrenal insufficiency occurring during septic shock: incidence, outcome, and relationship to peripheral cytokine levels. Am J Med 1995, 98:266-271.

6. Oppert M, Reinicke A, Gräf KJ, Barckow D, Frei U, Eckardt KU: Plasma cortisol levels before and during 'low-dose' hydrocortisone therapy and their relationship to hemodynamic improvement in patients with septic shock. Intensive Care Med 2000, 26:1747-1755.

7. Rydvall $A$, Brändström $A-K$, Banga $R$, Asplund $K$, Bäcklund $U$, Stegmayr BG: Plasma cortisol is often decreased in patients treated in an intensive care unit. Intensive Care Med 2000, 26:545-551.

8. Rivers EP, Gaspari M, Abi Saad G, Mlynarek M, Fath J, Horst HM, Wortsman J: Adrenal insufficiency in high-risk surgical ICU patients. Chest 2001, 119:889-896.

9. Annane D, Sebille V, Charpentier C, Bollaert P-E, Francois B, Korach J-M, Capellier G, Cohen Y, Azoulay E, Troché G, et al:: Effect of treatment with low doses of hydrocortisone and fludrocortisone on mortality in patients with septic shock. JAMA 2002, 288:862-871.

10. Hoen S, Asehnoune K, Brailly-Tabard S, Mazoit J-X, Benhamou D, Moine $P$, Edouard AR: Cortisol response to corticotropin stimulation in trauma patients. Influence of hemorrhagic shock. Anesthesiology 2002, 97:807-813.

11. Bollaert PE, Fieux F, Charpentier C, Lévy B: Baseline cortisol levels, cortisol response to corticotropin, and prognosis in late septic shock. Shock 2003, 19:13-15.

12. Manglik S, Flores E, Lubarsky L, Fernandez F, Chibber VL, Tayek JA: Glucocorticoid insufficiency in patients who present to the hospital with severe sepsis: a prospective clinical trial. Crit Care Med 2003, 31:1668-1675.

13. Marik PE, Zaloga GP: Adrenal insufficiency during septic shock. Crit Care Med 2003, 31:141-145.

14. Hamrahian AH, Oseni TS, Arafah BM: Measurements of serum free cortisol in critically ill patients. N Engl J Med 2004, 350:1629-1638.

15. Parikshak M, Shepard AD, Reddy DJ, Nypaver TJ: Adrenal insufficiency in patients with ruptured abdominal aortic aneurysms. $J$ Vasc Surg 2004, 39:944-950.

16. Den Brinker $M$, Joosten KFM, Liem O, De Jong FH, Hop WCJ, Hazelzet JA, Van Dijk M, Hokken-Koelega ACS: Adrenal insufficiency in meningococcal sepsis: bioavailable cortisol levels and impact of interleukin- 6 levels and intubation with etomidate on adrenal function and mortality. $J$ Clin Endocrinol Metab 2005, 90:5110-511.

17. Rady MY, Johnson DJ, Patel B, Larson J, Helmers : Cortisol levels and corticosteroid administration fail to predict mortality in critical illness. Arch Surg 2005, 140:661-668.

18. Widmer IE, Puder JJ, König C, Pargger H, Zerkowski HR, Girard J, Müller B: Cortisol response in relation to the severity of stress and illness. J Clin Endocrinol Metab 2005, 90:4579-4586.

19. Ho JT, Al-Musalhi H, Chapman MJ, Quach T, Thomas PD, Bagley CJ, Lewis JG, Torpy DJ: Septic shock and sepsis: a comparison of total and free plasma cortisol levels. J Clin Endocrinol Metab 2006, 91:105-14.

20. Braams R, Koppeschaar HPF, van de Pavoordt HDWM, van Vroonhoven TJMV: Adrenocortical function in patients with ruptured aneurysm of the abdominal aorta. Intensive Care Med 1998, 24:124-127.

21. Span LF, Hermus AR, Bartelink AK, Hoitsma AJ, Gimbrère JSF Smals AGH, Kloppenborg WC: Adrenocortical function: an indicator of severity of disease and survival in chronic critically ill patients. Intensive Care Med 1992, 18:93-96.

22. Malerba G, Romano-Girard F, Cravoisy A, Dousset B, Nace L, Lévy $B$, Bollaert P-E: Risk factors of relative adrenocortical deficiency in intensive care patients needing mechanical ventilation. Intensive Care Med 2005, 31:388-392.

23. Van der Voort PHJ, Gerritsen RT, Bakker AJ, Boerma EC, Kuiper MA, De Heide L: HDL-cholesterol level and cortisol response to synacthen in critically ill patients. Intensive Care Med 2003, 29:2199-2203.

24. Beishuizen A, Vermes I, Hylkema BS, Haanen C: Relative eosinophilia and functional adrenal insufficiency in critically ill patients. Lancet 1999, 353:1675-1676. 
25. Jackson WL Jr: Should we use etomidate as an induction agent for endotracheal intubation in patients with septic shock?: a critical appraisal. Chest 2005, 127:1031-1038.

26. Magill SS, Puthanakit T, Swoboda SM, Carson KA, Salvatori R, Lipsett PA, Hendrix CW: Impact of fluconazole prophylaxis on cortisol levels in critically ill surgical patients. Antimicrob Agents Chemother 2004, 48:2471-2476.

27. Pugeat $M$, Bonneton $A$, Perrot $D$, Rocie-Nicolas $B$, Lejeune $H$, Grenot C, Déchaud H, Brébant C, Motin J, Culleron C-Y: Decreased immunoreactivity and binding activity of corticosteroid-binding globulin in serum in septic shock. Clin Chem 1989, 35:1675-1679.

28. Beishuizen A, Thijs LG, Vermes I: Patterns of corticosteroidbinding globulin and the free cortisol index during septic shock and multitrauma. Intensive Care Med 2001, 27:1584-1591.

29. LeRoux CW, Chapman GA, Kong WM, Dhillo WS, Jones J, Alaghband-Zadeh J: Free cortisol index is better than serum total cortisol in determining hypothalamic-pituitary-adrenal status in patients undergoing surgery. J Clin Endocrinol Metab 2003, 88:2045-2048.

30. Le Gall J, Lemeshow S, Saulnier F: A new simplified acute physiology score (SAPS II) based on a European/North American multicenter study. JAMA 1993, 270:2957-2963.

31. Ferreira FL, Peres Bota D, Bross A, Mélot C, Vincent J-L: Serial evaluation of the SOFA score to predict outcome in critically ill patients. JAMA 2001, 286:1754-1758.

32. Yamauchi T, Harada T, Matsumara Y, Sueda K, Matsui N: Effect of acid-base disturbances on aldosterone secretion in man. $J$ Endocrinol Invest 1997, 20:576-579.

33. Vella A, Nippoldt TB, Morris JC: Adrenal hemorrhage: a 25-year experience at the Mayo Clinic. Mayo Clin Proc 2001, 76:161-168.

34. Catalano RD, Parameswaran V, Ramachandran J, Trunkey DD: Mechanisms of adrenocortical depression during Escherichia coli shock. Arch Surg 1984, 119:145-150. 